\title{
Strategi Direct Fundraising dengan Koin LAZISNU Padangsidimpuan
}

\author{
Risna Hairani Sitompul ${ }^{1}$, Siti Berlian Harahap ${ }^{2}$ \\ 1,2,Institut Agama Islam Negeri Padangsidimpuan \\ JL. H.T. Rizal Nurdin Km 4,5 Sihitang Kota Padangsidimpuan _ Sumatera Utara \\ Email: risnahairanistp@gmail.com ${ }^{1}$
}

\begin{abstract}
Fundraising strategy is a strategy carried out by an institution to raise funds such as the strategy carried out by LAZISNU Padangsidimpuan City in increasing ZIS fund receipts, which is useful for knowing the implementation of fundraising at LAZISNU. This study uses a qualitative approach with the type of field research. Sources of data in the form of primary data and secondary data. Collecting data with the method of observation, interviews and documentation. The data analysis technique used descriptive analysis method. The data validity technique was using triangulation, namely source triangulation and method triangulation. The results showed that LAZISNU Padangsidimpuan City implemented several strategies to raise funds. The fundraising strategy implemented by LAZISNU Padangsidimpuan City uses 2 methods, namely Direct Fundraising and Indirect Fundraising. Direct Fundraising consists of several programs, namely Zakat Pickup Service, Personal ZIS, Direct Mail, Nusantara Coin Movement and LAZISNU Glass Box, while the Indirect Fundraising method is carried out with the Socialization program.
\end{abstract}

Keywords : Fundraising, Zakat, LAZISNU

\begin{abstract}
ABSTRAK
Strategi Fundraising merupakan strategi yang dilakukan oleh sebuah lembaga untuk menghimpun dana seperti strategi yang dilakukan oleh LAZISNU Kota Padangsidimpuan dalam meningkatkan penerimaan dana ZIS, yang berguna untuk mengetahui implementasi fundraising pada LAZISNU. Penelitian ini menggunakan pendekatan kualitatif dengan jenis penelitian lapangan (field research). Sumber data berupa data primer dan data sukunder. Pengumpulan data dengan metode observasi, wawancara dan dokumentasi. Teknik analisis data menggunakan metode analisis deskriptif. Teknik keabsahan data dengan menggunakan triangulasi yaitu triangulasi sumber dan triangulasi metode. Hasil penelitian diketahui bahwa LAZISNU Kota Padangsidimpuan menerapkan beberapa strategi guna menghimpun dana. Strategi fundraising yang diterapkan oleh LAZISNU Kota Padangsidimpuan menggunakan 2 metode yaitu Direct Fundraising dan Indirect Fundraising. Direct Fundraising terdiri atas beberapa program yaitu Layanan Jemput Zakat, Personal ZIS, Direct Mail, Gerakan Koin Nusantara dan Kotak Kaca LAZISNU, sedangkan untuk metode Indirect Fundraising dilakukan dengan program Sosialisasi.
\end{abstract}

Kata Kunci : Fundraising, Zakat, LAZISNU 


\section{PENDAHULUAN}

Zakat Infak dan sedekah merupakan ibadah dalam agama Islam yang berkaitan erat dengan ekonomi, keuangan dan kemasyarakatan sehingga dalam pengelolaan dibutuhkan lembaga untuk mengelola dana ZIS khususnya penghimpunan dana. Penghimpunan dana merupakan roda penggerak sebuah organisasi pengelola zakat. Dalam penghimpunan dana setiap oraganisasi membutuhkan yang namanya strategi. Strategi penghimpunan dana zakat infak dan sedekah yang dilakukan LAZIS Padangidimpuan dilaksanakan yaitu strategi fundraising yang diterapkan oleh LAZISNU Kota Padangsidimpuan. Fundraising menggunakan 2 metode yaitu Direct Fundraising dan Indirect Fundraising. Direct Fundraising terdiri atas beberapa program yaitu Layanan Jemput Zakat, Personal ZIS, Direct Mail, Gerakan Koin Nusantara dan Kotak Kaca LAZISNU, sedangkan untuk metode Indirect Fundraising dilakukan dengan program Sosialisasi.

Proses penghimpunan dana terdapat berbagai cara untuk menarik sebuah kepercayaan masayarakat diantaranya yaitu melalui penggalangan dana, menciptakan sumber dana yang baru dengan membangun unit-unit usaha serte ekonomi yang menghasilkan pendapatan bagi sebuah lembaga dan sumber daya non financial berupa menerapkan strategi.

Proses fundraising sangat berpengaruh juga terhadap pengelolaan sebuah lembaga diantarannya yaitu lembaga zakat, infaq, dan sedeka. Adanya pengelolaan dari dana zakat, infaq maupun sedekah dapat membantu proses peningkatan kesejahteraan warga masyarakat dan dapat menurunkan angka kemiskinan. Strategi fundraising(penghimpunan danamaupun penyerahan dana)dapat membantu dalam peningkatan pengelolaan dana ZIS (Zakat, Infaq, Sedekah) pada LAZIS NU. Dalam sebuah pengorganisasiansistem kerja fundraising secara ber tim, kekompakan menjadi suatu hal yang penting. Terdapat banyak kelebihan jika fundraising dilakukan secara bertim atau bersama sama.

\section{METODE PENELITIAN}

\section{Jenis dan Pendekatan Penelitian}

Jenis Penelitian yang digunakan dalam penelitian ini adalah penelitian kualitatif deskriptif, yang mempunyai arti bahwa penelitian ini mengkaji dengan menggunakan cara kerja menjabarkan hasil penelitian berdasarkan penelitian dan pemaknaan terdata yang diperoleh cenderung data kualitatif, analisis data, bersifat induktif atau kualitatif, 
dan ini digunakan apabila data hasil penelitian tidak dapat diukur dengan angka atau dengan ukuran-ukuran lain yang bersifat eksak. Jenis penelitian dimaksudkan bahwa penelitian ini didasarkan pada system dan teknis pelaksanaan program KOIN NU, media sosial, rekening dan barcode pembayaran peduli dalam mengelola dana infaq guna kemaslahatan umat.

Pendekatan yang digunakan dalam penelitian ini adalah pendekatan kualitatif mendefenisikan metodologi kualitatif sebagai prosedurpenelitian yang menghasilkan data deksriptif berupa kata-kata tertulis atau lisan dari orang-orang dan prilaku yang diamati.

Penelitian kualitatif adalah jenis penelitian yang mengeksplorasi dan memahami makna di sejumlah individu atau kelompok yang berasal dari masalah social. Penelitian kualitatif secara umum dapat digunakan untuk penelitian tentang kehidupan masyarakat, sejarah, tingkah laku, konsep atau fenomena, masalah social dan lain-lain. Salah satu alasan mengapa menggunakan pendekatan kualitatif adalah pengamatn peneliti dimana metode ini dapat menemukan dan memahami apa yang tersembunyi dibalik fenomena yang kadangkala merupakan sesuatu yang sulit untuk dipahami.

Jenis penelitian kualitatif yang digunakan oleh peneliti dalam penelitian ini adalah studi kasus. Studi kasus merupakn studi yang mengeksplorasi suatu kasus secara mendalam, mengumpulkan informasi seara lengkap dengn menggunakan berbagai prosedur pengumpulan data berdasarkan waktu yang telah ditentukan. Kasus ini dapat berupa suatu peristiwa, aktivitas, proses dan program (Sa'diyah, 2020).

\section{Unit Analisis}

Unit analisis mencakup sesuatu yang berkaitan dengan focus dan komponen yang akan diteliti. Unit analisis dalam suatu penelitian dapat berupa individu, kelompok, organisasi, benda dan waktu tertentu sesuai dengan focus permasalahannya. Unit analisis suatu penelitian dapat berupa lembaga organisasi atau dapat pula lingkup organisasi skala kesil serta terbatas.

Berdasarkan pernyataan diatas maka dalam penelitian ini mencakup lokasi penelitian yang berisi lingkup organisasi yang akan diteliti dan subjek penelitian sebagai individu atau kelompok yang ada dalam penelitian tersebut.

\section{Lokasi Penelitian}

Lokasi penelitian ini diambil adalah LAZISNU Padangsidimpuan jalan Masjid Raya Baru No. 24 a Komplek Masjid Agung Al Abror Kota Padangsidimpuan 22711. 


\section{Subjek Penelitian}

Subjek penelitian yang dipilih dalam penelitian ini bertindak sebagai informan yang menjadi sumber inforasi bagi peneliti guna kebutuhan data penelitian yaitu Bapak Zulpan Harahap S.S, M.Pd, SM. Kom sebagai Ketua LAZISNU di Kota Padangsidimpuan.

\section{Data dan Jenis data}

Jenis data yang dimaksud adalah menyangkut informasi yang dapat berupa memperkaya dan informasi tentang permasalahan yang menjadi perhatian peneliti. Sumber yang diharapkan mampu menyediakan informasi yang diperlukan dalam penelitian ini yaitu

\section{Data Primer}

Data yang diperoleh atau dikumpulkan langsung dari narasumber yang berada di LAZISNU Padangsidimpuan, data tersebut secara langsung berhubungan dengan obyek penelitian dan mampu memberikan informasi yang dibutuhkan dalam penelitian ini, melalui wawancara yang berkaitan dengan permasalahan yang diteliti. Data primer antara lain : catatan hasil wawancara, dan data-data mengenai penelitian (Nasrudin, 2017).

\section{Data Sekunder}

Data yang diperoleh peneliti dari sumber yang ada. Dapat berupa bukti pencatatan, pembukuan, dan kumpulan data yang akan diteliti sebagai penguat dan pendukung .

\section{Teknik Pengumpulan}

Tekhnik pengumpulan data merupakan faktor penting demi keberhasilan penelitian. Hal ini berkaitan dengan bagaimana cara mengumpulkan data, siapa sumbernya, dan apa alat yang digunakan. Jenis sumber data adalah mengenai dari mana data diperoleh. Apakah data diperoleh dari sumber langsung (data primer) atau data diperoleh dari sumber tidak langsung (data sekunder).

\section{Teknik Analisi Data}

JISFIM: Journal of Islamic Social Finance Management, Volume 2, No 2 Tahun 2021 http://jurnal.iain-padangsidimpuan.ac.id/index.php/JISFIM 
Analisis data merupakan penguraian data dalam bentuk kalimat yang tersusun secara sistematis, jelas dan terperinci yang kemudian diinterreasikan untuk memperoleh suatu kesimpulan.

Metode yang dipergunakan dalam penelitian ini adalah analisis kualitatif deskriptif, yakni memberikan pengertian terhadap data yang dimaksud menurut kenyataan yang diperoleh dilapangan dan disusun serta diuraikan dalam bentuk kalimat per kalimat dimulai dai tahapan pengumpulan data dilanjutkan dengan reduksi data, display data dan tahapan terakhir penarikan kesimpulan dan verifikasi.

\section{Uji Keabsahan Data}

Keabsahan data dalam penelitian kualitatif merupakan salah satu bagian yang sangat penting untuk mengetahui derajat kepercayaan dari hasil penelitian yang telah dilakukan dengan menggunakan teknik triangulasi. Dalam pengumpulan data, maka data yang diperoleh akan lebih konsisten sehingga menjadi suatu data yang valid dan bisa dipertanggungjawabkan.

Agar penelitian dapat dipertanggung jawabkan maka diperlukan pengecekan dan apakah data yang disajikan valid atau tidak maka diperlukan teknik keabsahan atau kevalidan data.

Untuk memeriksa keabsahan data dalam penelitian ini, penelitian menggunakan teknik triangulasi. Triangulasi diartikan sebagai teknik pengumpulan data yang bersifat menggabungkan data dari berbagai teknik pengumpulan data dan sumber data yang telah ada.

Dalam penelitian ini menggunakan 2 macam triangulasi yaitu ; Triangulasi teknik, triangulasi teknik adalah peneliti menggunakan teknik pengumpulan data yang berbeda-beda untuk mendapatkan data dari sumber data yang sama; Triangulasi Sumber, triangulasi sumber unuk mendapatkan data dari sumber yang berbeda-beda denga teknik yang sama.

\section{HASIL DAN PEMBAHASAN}

NU CARE - LAZISNU

NU CARE-LAZISNU adalah rebranding dan/atau sebagai pintu masuk agar masyarakat global mengenal Lembaga Amil Zakat, Infak, dan Sedekah Nahdlatul Ulama (LAZISNU). NU CARE-LAZISNU berdiri pada tahun 2004 sebagai sarana untuk membantu masyarakat, sesuai amanat muktamar NU yang ke-31 di Asrama Haji Donohudan, Boyolali, Jawa Tengah. NU CARE secara yuridis-formal dikukuhkan 
oleh SK Menteri Agama No. 65/2005 untuk melakukan pemungutan Zakat, Infak, dan Sedekah kepada masyarakat luas (ISLAM, n.d.).

NU CARE-LAZISNU merupakan lembaga nirlaba milik perkumpulan Nahdlatul Ulama (NU) yang bertujuan, berkhidmat dalam rangka membantu kesejahteraan umat; mengangkat harkat sosial dengan mendayagunakan dana Zakat, Infak, Sedekah serta Wakaf (ZISWAF) (DAAIM, 2020).

Sejarah dan Perkembangan

1. 2004 (1425 Hijriyah) Lembaga Amil Zakat, Infak, dan Sedekah Nahdlatul Ulama (LAZISNU) lahir dan berdiri sebagai amanat dari Muktamar Nahdlatul Ulama (NU) yang ke-31, di Asrama Haji Donohudan, Boyolali, Jawa Tengah. Ketua Pengurus Pusat (PP) LAZISNU yang pertama adalah Prof. Dr. H. Fathurrahman Rauf, M.A., yakni seorang akademisi dari Universitas Islam Negeri (UIN) Syarif Hidayatullah, Jakarta.

2. 2005 (1426 Hijriyah) secara yuridis-formal LAZISNU diakui oleh dunia perbankan dan dikukuhkan oleh Surat Keputusan (SK) Menteri Agama No.65/2005.

3. 2010 (1431 Hijriyah) pada Muktamar Nahdlatul Ulama (NU) ke-32, di Makassar, Sulawesi Selatan, memberi amanah kepada KH. Masyhuri Malik sebagai Ketua PP LAZISNU dan menggantikan Prof. Dr. H. Faturrahman Rauf, MA. KH. Masyhuri dipercaya memimpin PP LAZISNU untuk masa kepengurusan 20102015. Hal itu telah diperkuat oleh SK Pengurus Besar Nahdlatul Ulama (PBNU) No.14/A.II.04/6/2010 tentang Susunan Pengurus LAZISNU periode 2010-2015.

4. 2015 (1436 Hijriyah) dengan berdasarkan Surat Keputusan Nomor: 15/A.II.04/o9/2015, Pengurus Pusat LAZISNU masa khidmat 2015-2020 diketuai oleh Syamsul Huda, SH.

5. 2016 (1437 Hijriyah) dalam upaya meningkatkan kinerja dan meraih kepercayaan masyarakat, NU CARE-LAZISNU menerapkan Sistem Manajemen ISO 9001:2015, yang dikeluarkan oleh badan sertifikasi NQA dan UKAS Management System dengan nomor sertifikat: 49224 yang telah diterbitkan pada tanggal 21 Oktober 2016. Dengan komitmen manajemen MANTAP (Modern, Akuntable, Transparan, Amanah dan Profesional).

Sampai saat ini, NU CARE telah memiliki jaringan pelayanan dan pengelolaan ZIS di 12 negara, di 34 provinsi, dan 376 kabupaten/kota di Indonesia. NU CARE sebagai lembaga filantropi akan terus berupaya untuk meningkatkan kepercayaan dari para donatur yang semua sistem pencatatan dan penyalurannya akan bisa dilihat secara real time melalui sistem IT (Ahmad, 2021).

JISFIM: Journal of Islamic Social Finance Management, Volume 2, No 2 Tahun 2021 http://jurnal.iain-padangsidimpuan.ac.id/index.php/JISFIM 


\section{Defenisi ZIS (Zakat, Infaq dan Sedekah)}

Menurut bahasa,zakat berarti suci, baik, tumbuh dan berkembang. Zakat menurut istilah syariah yaiu mengeluarkan harta yang telah mencapai syarat nisab dan haul untuk diserahkan kepda penerimanya.

Infaq yang berarti mengeluarka sesuatu harta untuk kebaikan. Infaq menurut istilah syariah, infaq merupakan pengeluaran sebagian harta atau pendapatan atau penghasilan sesuai yang diperintahkan dalam agama islam. Perbedaan antara zakat dan infaq bahwa zakat memiliki syarat nisab dan haul sedangkan infaq tidak memilikinya. Zakat diberikan pada delapan asnaf sedangkan infaq diberikan kepada siapapun.

Shodaqoh/Sedekah adalah pemberian sesuatu yang bersifat kebaikan, baik berupa barang maupun jasadari seseorang kepada orang lain tanpa mengharapkan suatu imbalan apapun selain ridha Allah. Hukum dan ketentuan shodaqoh sama dengan ketentuan infaq. Hanya saja jika infak berkaitan dengan materi. Shodaqoh/sedekah memiliki arti yang lebih luas (Rafiqi, 2019) Dengan demikian, zakat infak dansedekah dapat menjadi alternatif program pemerintah sebagaisumber dana untuk mengatasi kemiskinan (Roihanatasssa'adah, 2018).

\section{Penghimpunan dana}

Definisi Penghimpunan (Fundraising),Penghimpunan dalam dalam Kamus Besar Bahasa Indonesia (KBBI) adalah proses, cara, perbuatan mengumpulkan. Penghimpunan dana (fundraising) dapat pula diartikan sebagai proses mempengaruhi masyarakat baik perseorangan sebagai individu atau perwakilan masyarakat maupun lembaga agar menyalurkan dana atau sumber dayanya kepada sebuah organisasi atau lembaga (Hapsari, n.d.). Cara menghimpun dana Zakat, Infak, Sedekah ialah dengan tiga cara yaitu amil datang ke tempat muzaki, muzaki mentransfer dana ke Nurul Hayat dan yang terakhir muzaki mendatangi langsung ke kantor (KHAIRINA, 2019).

\section{Tujuan Penghimpunan (Fundraising)}

Ada beberapa hal yang menjadi tujuan dari fundraising bagi sebuah Lembaga Amil Zakat, Infak, dan Sedekah (LAZIS) adalahsebagai berikut; Pengumpulan dana. Pengumpulan dana mempunyai arti luas yaitu sumber daya (termasuk barang dan jasa) yang memiliki nilai materi dan dalam LAZIS ini sangat penting untuk mendukung 
program dan operasional yang telah dicanangkan; Penambahan jumlah muzakki dan donatur. LAZIS mempunyai data pertambahan muzakki dan donator sehingga akan mampu meningkatkan jumlah dana yangterhimpun; Meningkatkan citra LAZIS. Aktivitas fundraising yang dilakukan oleh sebuah LAZIS, baik langsung maupun tidak langsung akan membentuk citra lembaga itu sendiri akan membuat respon masyarakat positif dan akan semakin banyak menarik muzakki dan donator untuk ikut bergabung; Menjaga loyalitas muzakki dan donatur. LAZIS akan selalu menjaga loyalitas muzakki dan donatur merupakan tujuan yang tertinggi dan bernilai jangka panjang dengan memberikan bantuan sehingga akan memberikan kepuasan kepada muzakki dan donatur dengan pelayanan, program dan operasional LAZIS (Rafiqi, 2019).

\section{Metode Penghimpunan (Fundraising)}

Fundraising diartikan metode sebagai pola,bentuk atau cara-cara yang dilakukan oleh sebuah lembaga dalam rangka penggalangan dana dari masyarakat. Metode fundraising harus mampu memberikan kepercayaan, kemudahan, kebanggaan dan manfaat lebih bagi masyarakat donatur dan muzakki (Arifianto et al., 2021).

Metode ini pada dasarnya dapat dibagi kepada dua jenis yaitu: Direct Fundraising (secara langsung) dan Indirect Fundraising (secara tidak langsung).

\section{Direct Fundraising (secara langsung).}

Metode yang menggunakan teknik-teknik atau cara-cara yang melibatkan partisipasi donatur secara langsung, seperti: Layanan Jemput Zakat, Personal ZIS, Direct Mail, dan Gerakan KOIN LAZISNU.

Tabel 1. Jumlah KOIN NU yang tersebar di Kabupaten dan di Kota

\section{Sumatera Utara}

\begin{tabular}{|l|c|c|l|}
\hline $\begin{array}{c}\text { KABUPATENKOTA } \\
\text { SUMATERA UTARA }\end{array}$ & $\begin{array}{c}\text { Jumlah } \\
\text { KOIN }\end{array}$ & $\begin{array}{c}\text { Nomor } \\
\text { Tim }\end{array}$ & \multicolumn{1}{|c|}{ Wilayah } \\
\hline Kabupaten Asahan & 30 & 14 & Asahan - tebing \\
\hline Kabupaten Dairi & 42 & 60 & Sidiklang - barus \\
\hline Kabupaten Deli Serdang & 64 & 51 & Bandara - patumbak \\
\hline $\begin{array}{l}\text { Kabupatem Humbang } \\
\text { Hasundutan }\end{array}$ & 33 & 49 & Dolok sanggul - sidikalang \\
\hline Kabupaten Karo Labuhanbatu & 82 & 31 & Raya - berastagi \\
\hline Kabupaten Labuhanbatu & 64 & 19 & L.batu - labura \\
\hline $\begin{array}{l}\text { Kabupaten } \\
\text { Selatan an }\end{array}$ & 199 & 56 & Langga payung \\
\hline
\end{tabular}

JISFIM: Journal of Islamic Social Finance Management, Volume 2, No 2 Tahun 2021 http://jurnal.iain-padangsidimpuan.ac.id/index.php/JISFIM 


\begin{tabular}{|c|c|c|c|}
\hline & & 63 & Kotapinang - cikampak \\
\hline & & 47 & Paluta - kota pinang \\
\hline Kabupaten Lagkat & 89 & 44 & Langkat \\
\hline Kabupaten Mandailing Natal & 131 & 42 & Muara spongi - natal \\
\hline Kabupaten Padang Lawas & 36 & 50 & Palas - pasir pangaraian \\
\hline $\begin{array}{lll}\text { Kabupaten } & \text { Padanng } & \text { Lawas } \\
\text { Utara } & & \end{array}$ & 36 & 23 & Paluta - palas \\
\hline Kabupaten Samosir & 56 & 59 & Balige - siantar \\
\hline Kabupaten Simalungun & 106 & 53 & Sidamanik - perdagangan \\
\hline \multirow[t]{5}{*}{ Kabupaten Tapanuli Selatan } & 296 & 13 & Angkola - sipirok \\
\hline & & 18 & Parsalakan - batangtoru \\
\hline & & 46 & Sipirok - sipangimbar \\
\hline & & 11 & Tapsel - paluta \\
\hline & & 12 & Tapsel - madina \\
\hline Kabupaten Tapanuli Tengah & 121 & 24 & Tapteng - sibolga \\
\hline Kabupaten Tapanuli Utara & 57 & 17 & Pahae - siborong-borong \\
\hline Kota Binjai & 65 & 30 & Binjai \\
\hline \multirow[t]{14}{*}{ Kota Medan } & 759 & 21 & Amaliun - amplas \\
\hline & & 15 & Setia budi - pancing \\
\hline & & 16 & Ah. Nst - yamin - ginting \\
\hline & & 20 & Perjuangan - krakatau \\
\hline & & 21 & Amaliun - amplas \\
\hline & & 22 & Mandala -hm.joni \\
\hline & & 25 & J. Ginting - pwnu \\
\hline & & 26 & Ring road wali \\
\hline & & 27 & Ayahanda johor \\
\hline & & 28 & Selamat- pakam \\
\hline & & 29 & Karya - belawan \\
\hline & & 43 & Krakatau - klambir v \\
\hline & & 45 & Gaperta - asrama \\
\hline & & 55 & Masjid barat - gatsu \\
\hline Kota Padangsidimpuan & 977 & $\begin{array}{l}\text { 1 sampai } \\
10\end{array}$ & $\begin{array}{l}\text { Dalam kota } \\
\text { padangsidimpuan }\end{array}$ \\
\hline Kota Pematangsiantar & 61 & 52 & Siantar kota \\
\hline
\end{tabular}




\begin{tabular}{|l|c|c|l|}
\hline & & 57 & Siantar kota 2 \\
\hline Kota Sibolga & 2 & 48 & Sibolga - barus \\
\hline Kota Tebing Tinggi & 50 & 54 & Tebing - tamora \\
\hline & 3356 & & \\
\hline
\end{tabular}

Berdasarkan hasil wawancara dengan Bapak Zulpan Harahap, S.S, M.Pd, M.M, Pengurus Gerakan KOIN NU menyebarkan kotak kayu dan kotak kaca ke setiap warung warung seperti kios, rumah makan, restoran, counter HP, jual bahan bangunan, penginapan dan lain sebagainya yang ada di sekitaran Wilayah Kabupaten/Kota di Sumatera Utara. Berdasarkan data yang diambil dari LEZISNU, bahwa jumlah KOIN yang ada di Sumatera Utara yaitu ada 3694 yang terdiri 977 KOIN di Kota Padangsidimpuan dan 2717 KOIN berada di luar kota Padangsidimpuan. Data yang diambil disekitar Sumatera Utara walaupun data KOIN NU sudah menyebar sampai Sumatera Barat, Aceh dan Riau. Jumlah KOIN yang terbanyak ada di KotaPadangsidimpuan dengan menyediakan 977 KOIN dengan 10 tim dan di Kota medan tersebar 759 KOIN dengan 14 tim.

Tabel diatas dapat dilihat bahwa LAZISNU Padangsidimpuan memberikan layanan di jemput zakat dengan membagi beberapa tim seiap wilayah di propinsi Sumatera Utara dengan sejumlah gerakan KOIN NU berupa kotak kaca dan kayu (Astuti, 2020). Dana yang terhimpun akan dimanfaatkan untuk pemberdayaan masyarakat (Arifianto et al., 2021)

\section{Jumlah Dana yang dihimpun melalui Gerakan KOIN NU}

Berdasarkan gambar 1. bahwa tim yang memperoleh dana yang paling banyak dengan program Gerakan KOIN yaitu tim 19 yang mempunyai wilayah kabupaten labuhanbatu sampai labura selama tahun 2020 mencapai sekitar Rp. 28.631.200,oo. Kabupaten Labuhanbatu terkenal dengan penghasilan perkebunan kelapa sawit dan karet yang memiliki kedudukan yang strategis yaitu berada dijalur lintas timur sumatera dan berada dipersimpangan menuju provinsi Sumatera Barat dan Riau. Pada tahun 2020, penduduk kabupaten Labuhanbatu berjumlah 493.899 jiwa.

JISFIM: Journal of Islamic Social Finance Management, Volume 2, No 2 Tahun 2021 http://jurnal.iain-padangsidimpuan.ac.id/index.php/JISFIM 


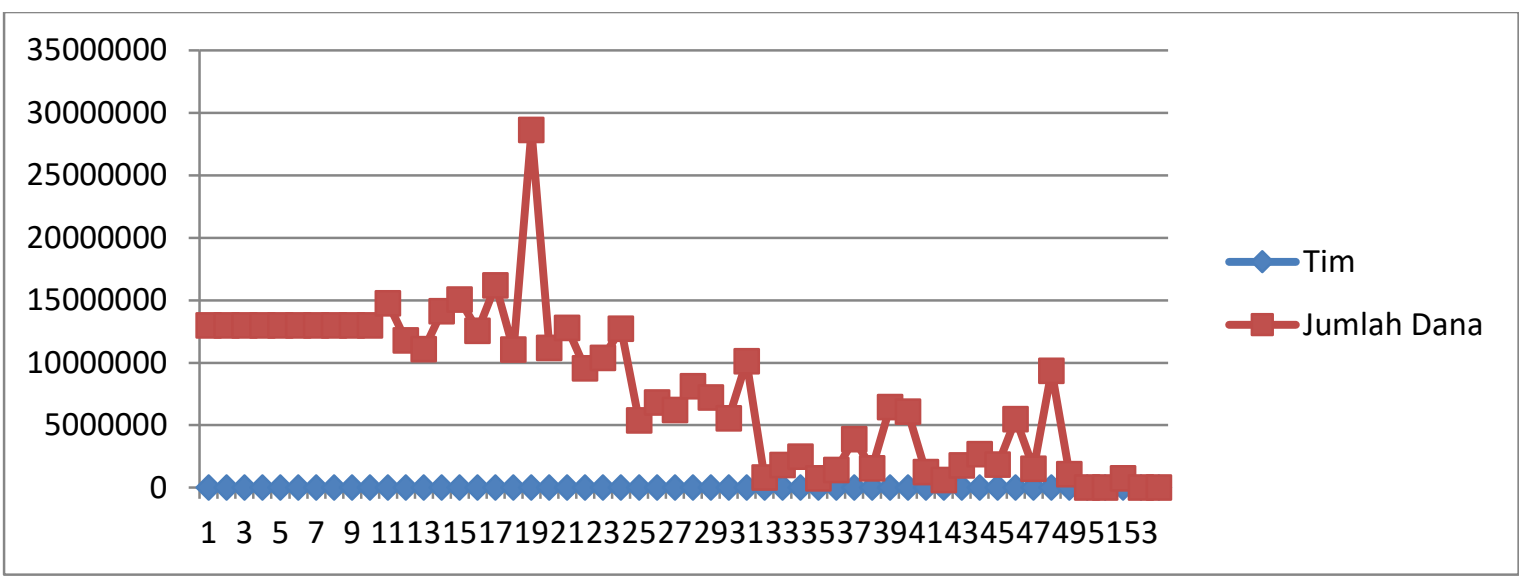

Gambar 1. Jumlah Dana yang dihimpun melalui Gerakan KOIN oleh masing-masing tim

Peran keefektifan LAZIS NU merupakan proses keberhasilan upaya pencapaian pengumpulan dana yang maksimal untuk disalurkan kembali kepada mustahiq dengan memberi pelayanan yang terbaik kepada muzakki maka akan memudahkan para muzakki untuk membayar zakat. Salah satu tugas dari organisasi pengelolaan zakat yaitu penghimpunan dana zakat. Menghimpun atau Penghimpunan dapat diartikan sebagai kegiatan pengumpulan dana dan sumber daya lainnya dari masyarakat (baik individu, kelompok, organisasi, perusahaan ataupun pemerintah) yang akan digunakan untuk membiayai program kegiatan operasional lembaga yang pada akhirnya dapat mencapai visi, misi dan tujuan dari lembaga tersebut (Fatimah, 2019) .

\section{Indirect Fundraising (secara tidak langsung)}

Metode yang menggunakan teknik-teknik atau cara-cara yang tidak melibatkan partisipasi donatur secara langsung, seperti contohnya: image compaign, penyelenggara event, menjalin relasi, melalui referensi, mediasi para tokoh, dan lainlain. Kedua metode tersebut dianggap mampu dalam meningkatkan penerimaan dana ZIS LAZISNU Padangsidimpuan (Mustaqim, 2019).

Faktor penghambat dalam penghimpunan dana zakat infak dan sedekag adalah: kurangnya sumber daya manusia dalam mengelola ZIS. dan pemahaman masyarakat tentang kewajiban berzakat. Faktor pendukung diantanya: masyarakat yang mayoritas muslim sehingga memudahkan mencari calon donator dan kecanggihan teknologi pada zaman sekarang sehingga memudahkan melakukan promosi dan sosialisasi (Rafi'i et al., 2020).

Konsep Fundraising lah yang digunakan sebuah organisasi dalam pengelolaan zakat, karena dana yang diperoleh dari sebuah organisasi digunakan untuk keberlangsungan dari sebuah organisasi tersebut, dapat mengurangi ketergantngan terhadap pihak tertentu dan untuk perluasan, pengembangan sebuah organisasi dan 
menciptakan suistainibility, dimana penggalangan dana bukan saja ditujukan untuk hari esok atau setaun kedepan (Ningsih, 2019).

Strategi fundraising yang dilakukan oleh Zakat Center dalam peningkatkan penerimaan dana ZIS serta mengetahui dan memahami faktor internal dan eksternal fundraising di dalam peningkatan penerimaan dana ZIS. Faktor internal yang mempengaruhi peningkatan penerimaan dana ZIS yaitu: (1) Penguatan keimanan oleh semua karyawan Zakat Center terutama staff fundraising; (2) Amilin Zakat Center harus mempunyai KOMAR; (3) Kekompakan funding agent Zakat Center; (4) Sarana dan prasarana Zakat Center. (5) Pelayanan Zakat Center. Sedangkan faktor eksternal yang mempengaruhi peningkatan penerimaan dana ZIS yaitu: (1) Persaingan dengan LAZ lain; (2) Kesadaran umat Islam dalam melaksanakan ZIS; (3) Dukungan pemerintah; (4) Lingkungan dengan penduduk mayoritas Islam (Anwar Sanusi \& Yufa Chaeranib, 2018).

\section{KESIMPULAN}

Penghimpunan dana merupakan roda penggerak sebuah organisasi pengelola zakat. Dalam penghimpunan dana setiap oraganisasi membutuhkan yang namanya strategi. Strategi penghimpunan dana zakat infak dan sedekah yang dilakukan LAZIS Padangidimpuan dilaksanakan yaitu strategi fundraising yang diterapkan oleh LAZISNU Kota Padangsidimpuan. Fundraising menggunakan 2 metode yaitu Direct Fundraising dan Indirect Fundraising. Direct Fundraising terdiri atas beberapa program yaitu Layanan Jemput Zakat, Personal ZIS, Direct Mail, Gerakan Koin Nusantara dan Kotak Kaca LAZISNU, sedangkan untuk metode Indirect Fundraising dilakukan dengan program Sosialisasi.

Berdasarkan data yang diambil dari LEZISNU, bahwa jumlah KOIN yang ada di Sumatera Utara yaitu ada 3694 yang terdiri 977 KOIN di Kota Padangsidimpuan dan 2717 KOIN berada di luar kota Padangsidimpuan. bahwa tim yang memperoleh dana yang paling banyak dengan program Gerakan KOIN yaitu tim 19 yang mempunyai wilayah kabupaten labuhanbatu sampai labura selama tahun 2020 mencapai sekitar Rp. 28.631.200,000.

Faktor penghambat dalam penghimpunan dana zakat infak dan sedekag adalah: kurangnya sumber daya manusia dalam mengelola ZIS. dan pemahaman masyarakat tentang kewajiban berzakat. Faktor pendukung diantanya masyarakat yang mayoritas muslim sehingga memudahkan mencari calon donator dan kecanggihan teknologi pada zaman sekarang sehingga memudahkan melakukan promosi dan sosialisasi. 


\section{DAFTAR PUSTAKA}

Ahmad, N. (2021). PEMBERDAYAAN EKONOMI MASYARAKAT MELALUI ZAKAT PRODUKTIF DI NU CARE-LAZISNU KABUPATEN BANYUMAS [PhD Thesis]. IAIN Purwokerto.

Anwar Sanusi, A. S., \& Yufa Chaeranib, Y. C. (2018). STRATEGI FUNDRAISING DALAM PENINGKATAN PENERIMAAN DANA ZAKAT INFAQ SHADAQAH DI ZAKAT CENTER THORIQOTUL JANNAH CIREBON. Jurnal Manajemen STIEC, 1(1), $61-74$.

Arifianto, C. F., Faroh, W. N., Tajuddien, R., \& Lestari, S. E. (2021). STRATEGI PENGUMPULAN DANA UNTUK ZAKAT, INFAK DAN SODAKOH (ZIS) UNTUK PEMBERDAYAAN MASYARAKAT DI KABUPATEN BOGOR. TA'AWUN, 1(1), 28-36.

Astuti, O. S. (2020). Implementasi penghimpunan dan pendistribusian dana zakat untuk kesejahteraan mustahik pada LAZISNU Kota Kediri [PhD Thesis]. Universitas Islam Negeri Maulana Malik Ibrahim.

DAAIM, M. (2020). Model Pengelolaan Zakat NU CARE-LAZISNU Tingkat Provinsi Jawa Tengah [PhD Thesis]. IAIN KUDUS.

Fatimah, F. (2019). Efektivitas Penghimpunan Dana Zakat, Infak dan Sedekah Melalui Layanan Jemput Bola Bagi Kepuasan dan Kepercayaan Muzakki di Lembaga Amil Zakat, Infak dan Sedekah Nahdlatul Ulama (LAZISNU) Majelis Wakil Cabang (MWC) Kecamatan Jombang.

Hapsari, P. S. (n.d.). Strategi Penghimpunan (Fundraising) Dana Zakat, Infak dan Sedekah (ZIS) Pada Lazis Griya Yatim dan Dhuafa (GYD).

ISLAM, J. S. D. K. (n.d.). SEJARAH LEMBAGA 'AMIL ZAKAT, INFAQ, DAN SHADAQAH NAHDLATUL ULAMA DAERAH ISTIMEWA YOGYAKARTA (LAZISNU DIY) TAHUN 2006- $2016 \mathrm{M}$. 
KHAIRINA, N. (2019). ANALISIS PENGELOLAAN ZAKAT, INFAK, SEDEKAH (ZIS) UNTUK MENINGKATKAN EKONOMI MUSTAHIK [PhD Thesis]. Universitas Islam Negeri Sumatera Utara Medan.

Mustaqim, M. K. (2019). Strategi fundraising program kaleng sedekah LAZISNU Kendal: Studi pada NU Care-LAZISNU Cabang Kendal [PhD Thesis]. UIN Walisongo.

Ningsih, W. P. (2019). Strategi fundraising dalam meningkatkan penerimaan dana ZIS oleh LAZISNU Limpung [PhD Thesis]. IAIN PEKALONGAN.

Rafi'i, R., Tarmizi, A., \& Badaruddin, B. (2020). ANALISIS FAKTOR-FAKTOR PENYEBAB KURANG MINAT MASYARAKAT MEMBAYAR ZAKAT DI LAZISNU KOTA JAMBI [PhD Thesis]. UIN Sulthan Thaha Saifuddin Jambi.

Rafiqi, I. (2019). Strategi Fundraising Zakat Infaq Shadaqah di LAZISNU dan LAZISMU Kabupaten Pamekasan [PhD Thesis]. UIN Sunan Ampel Surabaya.

Roihanatasssa'adah, N. (2018). UPAYA PENINGKATAN PENGHIMPUNAN DANA ZAKAT, INFAK, DAN SEDEKAH (ZIS) OLEH LEMBAGA AMAL ZAKAT INFAK DAN SHADAQAH NAHDLATUL ULAMA (LAZISNU) KABUPATEN KUDUS [PhD Thesis]. IAIN KUDUS.

Sa'diyah, Y. H. (2020). Implementasi regulasi zakat terhadap kinerja amil zakat: Studi di kantor LAZISNU cabang Nganjuk [PhD Thesis]. Universitas Islam Negeri Maulana Malik Ibrahim. 